\title{
IS THERE ANY CHANCE TO INCREASE PUPILS' INTEREST IN SCIENCE SUBJECTS?
}

\author{
Milan Kubiatko \\ Masaryk University, Czech Republic \\ E-mail: mkubiatko@gmail.com
}

Dear colleagues, dear readers of the journal, as a new member of the editorial board I was requested to write of an editorial in this issue. Nowadays, in the science world, especially in the science education world exist many problems, which are or which will be investigated. The part of them is presented in this number. We are meeting with the results with science research every day, the results are presented in different form of resources, from print form to electronic form. So these results are not very flattering, mainly the interest about science subjects is decreasing and the way, how this trend to stop is still not found. Some universities published reports, where is showed, the number of students, whose study some science subject is rapidly decreasing. With respect to important meaning of the science subjects for the development of society is necessary this situation to solve. The interest about science subjects is investigated very often, in the context of science research. The investigators are using different methods of data acquiring, at different respondents, in different types of schools. All investigations are trying to find out the reasons of the lack of interest and also find out possible solution, how to change this situation and support the interest of pupils and students about science subjects. One of the factors, which can influence the low interest, is the manner of teaching. The many investigators quote, the predominant style is teacher-centred teaching, where the pupil or student is the only passive acceptor of different kinds of information. So, maybe, the one way is to use innovative teaching method pupil-centred oriented, which can cause the increasing of the interest about science subjects. The one of obstacles, which can prevent to insert innovative methods, is the low number of teaching hours of science subjects. In many countries there is only one hour of biology (for example) per week. Of course, there is necessary to see the motivation of teachers. When the pupils or students see motivated teacher, his/her interest about science subject can be increased by the motivational effect of the teacher. Next, the activities connected with pupilcentred style of teaching can contain discussion. Children are curious, so the teachers could provoke a discussion about some science problems and answer on pupils' questions and also point out the unsolved problems regarding to science and on the base of it show to pupils, the science needs persons, whose are and will be interested in the solving of science problems. The next activity, which can increase is creative writing. Teachers could get them to make fictional stories about what they learnt in science. It can help them remember the facts better because the mind remembers stories better than just a list of facts. It adds an element of creativity and fun in learning Science. In fact, many memory techniques employ such creative technique to add fun to studying. Another way could be a portfolio. A portfolio is a powerful way of making learning tangible. Teachers can get pupils to collect all his works and ideas, take photos of their experiments and include them into the portfolio. With time, pupils can see his portfolio grow as a testament to his learning journey. They cannot but feel proud of all the work they have done. This will help boost his morale and remind him of the exploratory nature in science. Next, there is also important the work with mistakes. When attempting experiments and hands on activities, there seems to be an expectation that we must get the correct results. But it doesn't have to be that 
PROBLEMS

OF EDUCATION

IN THE $21^{\text {st }}$ CENTURY

Volume 43,2012

way. Actually in science, there is no such thing as a failed experiment. Even if your pupil didn't get the expected results, there is learning in what didn't go right, and why. All these elements and also other elements are incorporated in the inquiry-based science education (IBSE). In IBSE, learners are encouraged to learn through exploring, discovery and investigation. There is a connection between the learning and home environment in such a way that children are able to identify with the learning process. IBSE is in practice when pupils are developing concepts that enable them to understand the scientific aspects of the world around them through their own thinking, using critical and logical reasoning about evidence that they have gathered. This may involve them in the first-hand manipulation of objects and materials and observation of events. Teachers are leading pupils to develop the skills of inquiry and an understanding of science concepts through the pupils' own activity and reasoning. From the previous information is obvious, there is a chance to increase pupils' interest in science subjects, but there are necessary to apply new methods and forms in the teaching process of science subjects.

Received: April 18, 2012

Accepted: May 25, 2012
Milan Kubiatko

$\mathrm{PhD}$, Assistant Professor at Institute for Research in School Education at FacuIty of Education, Masaryk University in Brno, Czech Republic.

E-mail: mkubiatko@gmail.com

Website: http://www.kubiatko.eu/ 